\title{
Early and midterm results of transapical and right axillary artery cannulation for acute aortic dissection
}

Takamitsu Terasaki, Tamaki Takano*, Taishi Fujii, Tatsuichiro Seto, Yuko Wada, Yoshinori Ohtsu

and Kazunori Komatsu

\begin{abstract}
Background: We combined transapical cannulation and right axillary artery cannulation in the repair of acute type A aortic dissection in order to reduce mortality and morbidity in the presence of risk of malperfusion. Early and midterm outcomes were evaluated.

Methods: Between October 2009 and March 2012, 23 aortic dissection patients (age, 54.3 \pm 13.5 years) received graft replacement using a combination of transapical and right axillary artery cannulation. Preoperative malperfusion was present in 16 patients (69.6\%). Cardiopulmonary bypass was initiated with axillary artery cannulation applied via the right axilla and right atrial drainage, then aotric cannulation applied via the left ventricular apex. We retrospectively investigated mortality and morbidity as well as cardiac function, which were evaluated echocardiographically during hospitalization and once a year postoperatively.

Results: All patients received total arch replacement. In-hospital mortality was 4.3\%, and no patient developed intraoperative malperfusion. Intraoperative stroke occurred in one patient (4.3\%), and three patients (13.0\%) suffered from delayed stroke (10-24 days). These delayed strokes might have resulted from cardiogenic thrombus, although no intracardiac thrombus was found. Mean ejection fraction was $66.1 \pm 10.9 \%$ in the early postoperative period and $73.1 \pm 8.7 \%$ midterm. There was no left ventricular asynergy or intracardiac thrombus seen on either early or midterm echocardiography.
\end{abstract}

Conclusion: Transapical cannulation with right axillary artery cannulation is a safe and effective procedure that can reduce operative risk associated with aortic dissection. Although transapical cannulation does not appear to impair cardiac function, it may confer a risk of delayed stroke.

Keywords: Aortic dissection, Cannulation, Aortic surgery, Complication

\section{Background}

It is sometimes difficult to choose a cannulation site that will avoid organ malperfusion in acute type A aortic dissection (AAD) when the true lumen is compressed by a false lumen and femoral artery cannulation presents risks of organ malperfusion and brain infarction because of retrograde blood flow and embolism [1,2].

Transapical cannulation (TAC) had been introduced as a useful application of cardiopulmonary bypass (CPB) in the presence of a severely atherosclerotic ascending

\footnotetext{
*Correspondence: ttakano-ths@umin.ac.jp

Department of Cardiovascular Surgery, Shinshu University School of Medicine, 3-1-1 Asahi, Matsumoto 390-8621, Japan
}

aorta [3]. Some authors have reported that TAC can be an alternative technique for cannulation during AAD repair, especially since the introduction of transesophageal echocardiography (TEE) to ensure the location of the cannula [4-7], but mortality (7.7-18.8\%) and rate of cerebral complications $(5.8-15.8 \%)$ remain high. The axillary artery is an alternative cannulation site that can provide antegrade blood flow during $\mathrm{CPB}$ [8], and its efficacy at reducing the risk of stroke during AAD repair has been documented $[9,10]$.

We combined TAC and right axillary artery cannulation (RAAC) for the repair of AAD in the presence of a risk of malperfusion. In this study, we evaluated early 
and midterm outcomes of AAD repair employing a combination of TAC and RAAC.

\section{Methods}

Between October 2009 and March 2012, 71 AAD patients underwent aortic graft replacement in Shinshu University Hospital. Of 71 patients, 24 (33.8\%) received graft replacement with combined TAC/RAAC. In one patient, TAC was abandoned intraoperatively because of left ventricle distention from massive aortic valve regurgitation, so 23 of 24 TACs $(95.8 \%)$ were completed and analyzed.

Indications for TAC and RAAC were one or more contraindications for femoral cannulation, including iliofemoral artery dissection and presence of abdominal aortic or iliac artery aneurysm. Mean patient age was $54.3 \pm 13.5$ years, and male/female ratio was $15 / 8$. Clinical background and preoperative conditions are shown in Table 1. Preoperative malperfusion of one or more organs was present in 16 patients (69.6\%).

We performed total arch replacement in patients aged $\leq 70$ years. Hemi-arch replacement was performed in patients aged over 70 when the initial tear was found at the ascending aorta. RAAC was performed by exposing the right axillary artery through a 4- to 6-cm skin incision in the right armpit and inserting a 10- to14-Fr DLP ${ }^{\circ}$ onepiece pediatric arterial cannula (Medtronic, Minneapolis, $\mathrm{MN}$ ) through the artery. Right atrial drainage achieved using a single venous cannula, and the patient was then placed on CPB. TAC was accomplished with a 21-Fr Soft-Flow ${ }^{\circ}$ Extended arterial cannula (Terumo, Tokyo, Japan) through the left ventricular apex. After the location of cannula tips was confirmed by TEE, blood flow was increased to maintain adequate perfusion.

To protect the brain and abdominal organs, we used selective cerebral perfusion and hypothermic circulatory arrest with a rectal temperature of $25^{\circ} \mathrm{C}$. Open distal anastomosis was performed first, and total $\mathrm{CPB}$ was then restarted through a side branch of the vascular graft.

Table 1 Preoperative patients characteristics

\begin{tabular}{ll}
\hline & Cases $(\mathrm{n}=23)$ \\
\hline Age $(\mathrm{y})$ & $54.3 \pm 13.5$ \\
Male/Female sex & $15 / 8$ \\
Loss of conciousness & $5(20.8 \%)$ \\
Aortic regurgitation $>$ mild & $6(25.0 \%)$ \\
Pericardial efusion & $5(21.7 \%)$ \\
Malperfusion & $16(69.6 \%)$ \\
Cerebral & $8(34.8 \%)$ \\
Myocardial & $2(8.7 \%)$ \\
Limb & $10(43.5 \%)$ \\
Mesenteric & $1(4.3 \%)$ \\
\hline
\end{tabular}

TAC: trans apical cannulation, RAAC: right axillary artery cannulation.
After the proximal anastomosis, the apical incision was closed using 4-0 polyvinylidene fluoride suture with felt pledgets. Neck vessels were individually reconstructed during rewarming.

We retrospectively investigated in-hospital mortality and morbidity. Cardiac function and thrombus around the left ventricular apex was evaluated using echocardiography postoperatively during the hospital stay and once a year after discharge from the hospital. Statistical comparison of postoperative left ventricular ejection fraction between early and midterm periods was conducted using the Student $t$ test using IBM SPSS statistics 21.0 software (IBM Corp, Armonk, NY USA). The Shinshu University School of Medicine Institutional Ethics Committee approved this study.

\section{Results and discussion}

Total arch replacement was performed in all patients. Concomitant procedures were root reconstruction in four patients (17.4\%), aortic valve replacement in one (4.3\%), and coronary artery bypass in three (13.0\%) (Table 2).

In-hospital mortality was $4.3 \%$; one patient died on the 6th postoperative day because of low-output syndrome. $\mathrm{He}$ had presented with severe bilateral limb ischemia and undergone total arch replacement with coronary artery bypass grafting (Table 2 ).

No patient developed intraoperative malperfusion of the limbs or abdominal organs requiring additional operation. One patient, whose celiac artery was obstructed by the dissection on preoperative computed tomography, had temporary liver dysfunction postoperatively. Intraoperative stroke occurred in one patient $(4.3 \%)$, and three patients (13.0\%) suffered from stroke on postoperative days 10-24

Table 2 Operation and results

\begin{tabular}{llc}
\hline & & \multicolumn{1}{c}{$\begin{array}{l}\text { Cases } \\
(\mathrm{n}=23)\end{array}$} \\
\hline $\begin{array}{lll}\text { - Procedures } \\
\text { procedures }\end{array}$ & Total arch replacement & $23(100 \%)$ \\
& Root recontraction & $4(17.4 \%)$ \\
& Aortic valve replacement & $1(4.3 \%)$ \\
& CABG & $3(13.0 \%)$ \\
& In-hospital mortality & $1(4.3 \%)$ \\
& Intraoperative srtoke & $1(4.3 \%)$ \\
& $\begin{array}{l}\text { Delayed stroke } \\
\text { Intraoperative organ } \\
\text { malperfusion }\end{array}$ & $3(13.0 \%)$ \\
& Newly required hemodialysis & 0 \\
& Revision for bleeding & $2(8.7 \%)$ \\
& Prolonged ventilation ( $>72 \mathrm{~h})$ & $3(13.0 \%)$ \\
& Hospital stay (d) & $35.7 \pm 18.6$ \\
\hline CABG: Coronary artery bypass grafting. &
\end{tabular}


Table 3 Patient characteristics of delayed stroke cases

\begin{tabular}{lcllclll}
\hline Patient & Age $(\mathrm{y})$ & Sex & Operation & Onset of stroke $(\mathrm{d})$ & Atrial fibrillation & Intracardiac thrombus & Cervical artery dissection \\
\hline 1 & 35 & Male & Total arch & 24 & no & no & no \\
2 & 63 & Male & Total arch & 18 & no & no & no \\
3 & 66 & Female & Total arch & 10 & no & no & yes \\
\hline
\end{tabular}

(Table 3), although they recovered to care for themselves and discharged from hospital by walk.

Postoperative echocardiography was performed in 21 patients (95.5\%) $12.4 \pm 3.8$ days after the operation. Mean ejection fraction was $66.1 \pm 10.9 \%$. No new left ventricular asynergy or intracardiac thrombus developed postoperatively (Table 4).

No patient died or developed stroke during the follow up period (23.6 \pm 8.5 months). Two patients received additional vascular surgery (one for aneurysm of the thoracic descending aorta and the other for abdominal aortic aneurysm). Transthoracic echocardiography was able to be performed in 17 of 22 patients $(77.3 \%)$ during the midterm period, $15.6 \pm 8.1$ months after the operation. Mean ejection fraction was $73.1 \pm 8.7 \%$. We found no left ventricular asynergy, intracardiac thrombus, or left ventricular aneurysm (Table 4).

Surgical mortality for AAD has been reported to be $23.8 \%$ [11], increasing to $43.7 \%$ when the patient presents with organ malperfusion preoperatively [12]. Mortality reaches $63.2 \%$ in cases complicated by mesenteric malperfusion [13]. Organ ischemia, caused by occlusion by a dissection flap or thrombus in the branch arteries, affects $15-40 \%$ of patients with AAD [14]. In the present study, in-hospital mortality was $4.3 \%$ and no patient developed intraoperative malperfusion, even though the rate of preoperative malperfusion was $69.6 \%$ and relatively higher than that seen in the reports mentioned above. The combination of RAAC with TAC seemed to prevent intraoperative malperfusion during AAD surgery. RAAC is effective to reduce the risk of stroke, but it could not achieve total blood flow alone. The initial perfusion with RAAC would make true lumen

Table 4 Echocardiography data

\begin{tabular}{lccl}
\hline Variables & $\begin{array}{l}\text { Early period } \\
(\mathrm{n}=21)\end{array}$ & $\begin{array}{l}\text { Midterm period } \\
(\mathrm{n}=17)\end{array}$ & P value \\
\hline LVEF (\%) & $66.1 \pm 10.9$ & $73.1 \pm 8.7$ & 0.053 \\
LVDd (mm) & $44.6 \pm 7.0$ & $46.7 \pm 4.3$ & 0.44 \\
Aortic regurgitation & 0 & 0 & \\
$>$ mild (n) & & & \\
Asynergy (n) & 1 & 1 & \\
Pseudoaneurysm (n) & 0 & 0 & \\
Intracardiac thrombus $(\mathrm{n})$ & 0 & 0 & \\
\hline
\end{tabular}

LVEF: Left ventricular ejection fraction, LVDd: Left ventricular diastolic dimension. more patent and help establish total circulatory support after TAC is added. In a report on TAC perfusion without RAAC for AAD repair, Matsushita et al. described the occurrence of malperfusion in four out of 52 patients on initiation of CPB [7]. In that study, applying TAC may have caused hemodynamic instability owing to hypotension and arrhythmia occurring during cannulation and TEE confirmation of positioning. Although TAC is not a technically demanding procedure, the left ventricular apex does need to be lifted up. However, no patients presented any injury in the fragile aorta of AAD in applying TAC. We were able to establish $\mathrm{CPB}$ under safe and stable conditions with the help of RAAC prior to TAC. RAAC can provide appropriate support for the application of TAC, especially for hemodynamically unstable patients.

The stroke rate in the present study is comparable to the $5.8-15.8 \%$ observed in previous studies using TAC alone for AAD surgery [5,7], with one case of intraoperative stroke $(4.3 \%)$ and three cases of stroke occurring more than 10 days postoperatively (13.0\%). Another study reported that delayed stroke occurred in $25.3 \%$ of patients with cervical artery dissection without TAC [15]. In the present study, one of three patients with delayed stroke presented with cervical artery dissection; the other two cases did not. These delayed strokes may have been be caused by cardiogenic thrombus, although no thrombus was found in cardiac chambers on postoperative transthoracic echocardiograpy (TTE). It is important to be aware of the risk of delayed stroke after AAD surgery with TAC.

We found no LV asynergy or pseudoaneurysm on the apex and no aortic valve regurgitation in the early and midterm postoperative periods by TTE. Neither pseudoaneurysm nor intracardiac thrombus was seen on follow up echocardiography. Left ventricular ejection fraction increased slightly in the midterm period even though the left ventricular apex had received iatrogenic injury from passing of the cannula and suturing. There are few reports of postoperative cardiac function after surgery employing TAC. In our experience, TAC does not affect cardiac function in the early and midterm periods after repair of $\mathrm{AAD}$, but a long-term follow-up study is warranted.

\section{Conclusions}

In conclusion, the combination of TAC and RAAC is safe and effective at reducing the risk of malperfusion in 
AAD. TAC may not affect cardiac function in the early and midterm postoperative periods but may confer a stroke risk after 10 days postoperatively.

\section{Abbreviations}

AAD: Acute type A aortic dissection; TAC: Transapical cannulation; CPB: Cardiopulmonary bypass; RAAC: Right axillary artery cannulation; TTE: Transthoracic echocardiograpy.

\section{Competing interests}

The authors declare that they have no competing interests.

\section{Authors' contributions}

$\Pi T$ presented design of the report and completed the manuscript. TF, TS, YW, ON, and KK are in charge of patient care. Tा directed all the work. All authors read and approved the final manuscript.

Received: 27 August 2014 Accepted: 26 December 2014

Published online: 09 January 2015

\section{References}

1. Shimokawa T, Takanashi S, Ozawa N, Itoh T. Management of intraoperative malperfusion syndrome using femoral artery cannulation for repair of acute type A aortic dissection. Ann Thorac Surg. 2008:8:1619-24.

2. Goldstein LJ, Davies RR, Rizzo JA, Davila JJ, Cooperberg MR, Shaw RK, et al. Stroke in surgery of the thoracic aorta: incidence, impact, etiology, and prevention. J Thorac Cardiovasc Surg. 2001;122:935-45.

3. Golding LA. New cannulation technique for the severely calcified ascending aorta. J Thorac Cardiovasc Surg. 1985;90:626-7.

4. Yamamoto S, Hosoda Y, Yamasaki M, Ishikawa N, Fuchimoto K, Fukuda T. Transapical aortic cannulation for acute aortic dissection to prevent malperfusion and cerebral complications. Tex Heart Inst J. 2001;28:42-3.

5. Wada S, Yamamoto S, Honda J, Hiramoto A, Wada H, Hosoda Y. Transapical aortic cannulation for cardiopulmonary bypass in type A aortic dissection operations. J Thorac Cardiovasc Surg. 2006;132:369-72.

6. Sosnowski AW, Jutley RS, Masala N, Alexiou C, Swanevelder J. How I do it: transapical cannulation for acute type-A aortic dissection. J Cardiothorac Surg. 2008;3:4

7. Matsushita A, Manabe S, Tabata M, Fukui T, Shimokawa T, Takanashi S. Efficacy and pitfalls of transapical cannulation for the repair of acute type A aortic dissection. Ann Thorac Surg. 2012;93:1905-9.

8. Sabik JF, Lytle BW, McCarthy PM, Cosgrove D. Axillary artery: An alternative site of arterial cannulation for patients with extensive aortic and peripheral vascular desease. J Thorac Cardiovasc Surg. 1995;109:885-91.

9. Numata S, Ogino H, Sasaki H, Hanafusa Y, Hirata M, Ando M, et al. Total arch replacement using antegrade selective cerebral perfusion with right axillary artery perfusion. Eur J Cardiothorac Surg. 2003;23:771-5.

10. Minatoya K, Ogino H, Matsuda H, Sasaki H. Rapid and safe establishment of cardiopulmonary bypass in repair of acute aortic dissection: improved results with double cannulation. Interact Cardiovasc Thorac Surg. 2008; 7:951-3.

11. Trimarchi S, Eagle KA, Nienaber CA, Rampoldi V, Jonker FH, De Vincentiis $C$, et al. International Registry of Acute Aortic Dissection Investigators: Role of age in acute type $A$ aortic dissection outcome: report from the International Registry of Acute Aortic Dissection (IRAD). J Thorac Cardiovasc Surg. 2010;140:784-9.

12. Pacini D, Leone A, Belotti LM, Fortuna D, Gabbieri D, Zussa C, et al. On behalf of RERIC (Emilia Romagna Cardiac Surgery Registry) Investigators: Acute type A aortic dissection: significance of multiorgan malperfusion. Eur J Cardiothorac Surg. 2013;43:820-6.

13. Di Eusanio M, Trimarchi S, Patel HJ, Hutchison S, Suzuki T, Peterson MD, et al. Clinical presentation, management, and short-term outcome of patients with type A acute dissection complicated by mesenteric malperfusion: Observations from the International Registry of Acute Aortic Dissection. J Thorac Cardiovasc Surg. 2013;145:385-90.
14. Charlton-Ouw KM, Sritharan K, Leake SS, Sandhu HK, Miller 3rd CC, Azizzadeh A, et al. Management of limb ischemia in acute proximal aortic dissection. J Vasc Surg. 2013;57:1023-9.

15. Lichy C, Metso A, Pezzini A, Leys D, Metso T, Lyrer P, et.al.: Predictors of delayed stroke in patients with cervical artery dissection. Int J Stroke. 2012. doi: 10.1111/j.1747-4949.2012.00954x.

\section{Submit your next manuscript to BioMed Central and take full advantage of:}

- Convenient online submission

- Thorough peer review

- No space constraints or color figure charges

- Immediate publication on acceptance

- Inclusion in PubMed, CAS, Scopus and Google Scholar

- Research which is freely available for redistribution

Submit your manuscript at www.biomedcentral.com/submit 